\title{
Reduction-Alkylation Strategies for the Modification of Specific Monoclonal Antibody Disulfides
}

\author{
Michael M.C. Sun, Kevin S. Beam, Charles G. Cerveny, Kevin J. Hamblett, Richard S. \\ Blackmore, Michael Y. Torgov, Felicia G.M. Handley, Peter D. Senter, and Stephen C. Alley ${ }^{\star}$ \\ Seattle Genetics, Inc. 21823 30 th Drive SE, Bothell, WA 98021
}

\section{Abstract}

Site-specific conjugation of small molecules and enzymes to monoclonal antibodies has broad utility in the formation of conjugates for therapeutic, diagnostic, or structural applications. Precise control over the location of conjugation would yield highly homogenous materials that could have improved biological properties. We describe for the first time chemical reduction and oxidation methods that lead to preferential cleavage of particular monoclonal antibody interchain disulfides using the antiCD30 IgG1 monoclonal antibody cAC10. Alkylation of the resulting cAC10 cysteine thiols with the potent antimitotic agent monomethyl auristatin E (MMAE) enabled the assignment of drug conjugation location by purification with hydrophobic interaction chromatography followed by analysis using reversed-phase HPLC and capillary electrophoresis. These analytical methods demonstrated that treating $\mathrm{cAC} 10$ with reducing agents such as DTT caused preferential reduction of heavy-light chain disulfides, while reoxidation of fully reduced cAC10 interchain disulfides caused preferential reformation of heavy-light chain disulfides. Following MMAE conjugation, the resulting conjugates had isomeric homogeneity as high as $60-90 \%$, allowing for control of the distribution of molecular species. The resulting conjugates are highly active both in vitro and in vivo, and are well tolerated at efficacious doses.

Monoclonal antibodies (mAbs) have been used extensively as carriers of fluorophores, radionuclides, cytotoxic agents, and enzymes, yielding conjugates that find utility in therapeutic (1-3) and imaging applications (4,5), ELISA-based assays (6), as well as for the investigation of protein structure and dynamics (7). The methods employed for making mAbbased conjugates can be classified in two general categories: those that involve the random modification of $\mathrm{mAb}$ amino acid residues, and those that are highly regioselective. Examples of random modification procedures include the acylation of lysine $\varepsilon$-amino groups (8), alkylation of tyrosines (9), and amidation of carboxylates (10). The biological and functional properties of these conjugates are often acceptable, however random modification of mAbs may impair antigen binding and leads to conjugate heterogeneity.

In the past several years, a number of selective methods have been described to introduce molecules of interest onto mAbs. The ability to control the location and stoichiometry of conjugation can significantly improve the properties of mAb conjugates in some applications. The greatest selectivities are obtained using recombinant technologies for the production of fusion proteins (11-14). Selective modification has also been reported for such chemically based methods as reductive amination of oxidized mAb carbohydrates (15), photoaffinity labeling of unconventional mAb binding sites (16), and reduction-alkylation of antibody interchain disulfides $(17,18)$. 
We have previously described the preparation of mAb-drug conjugates for use as antitumor agents $(17,19)$. The potent antimitotic agent monomethyl auristatin $\mathrm{E}$ (MMAE) was conjugated to the chimeric anti-CD30 mAb cAC10, an IgG1 mAb with 4 interchain disulfides (Figure 1). Conjugates were formed through full reduction of all interchain disulfides, followed by alkylation with the drug-linker complex. The resulting mAb-drug conjugates were homogeneous in composition, with about 8 drugs $/ \mathrm{mAb}$. Since $\mathrm{mAb}$ interchain disulfides are distant from the antigen binding site and are generally not required to maintain mAb integrity (20), this site-specific conjugation strategy yielded conjugates that were potent and selective for CD30-positive hematologic malignancies $(17,19)$.

We recently demonstrated that drug-load stoichiometry significantly influenced conjugate pharmacokinetics, and that conjugates with fewer drugs/mAb had larger therapeutic windows (21). Specifically, conjugates with $4 \mathrm{drugs} / \mathrm{mAb}$ were highly active and significantly less toxic than their counterparts with $8 \mathrm{drugs} / \mathrm{mAb}$. However, such partially-loaded conjugates are not homogeneous, and the number of drugs on each $\mathrm{mAb}$ vary from $0-8$, with several isomers at each drug substitution level. In order to minimize the heterogeneity of these partially loaded conjugates with 4 drugs $/ \mathrm{mAb}$, we explored various reduction/alkylation strategies and evaluated the distribution of species formed. We recognized that the absolute drug loading and the isomeric distribution could play a role in efficacy and toxicity. However, the literature does not describe how to chemically control the isomeric distribution of drug loading, nor does it illustrate how to determine which of the various $\mathrm{mAb}$ thiols are drug substituted. To address these issues, analytical technologies were established to determine the sites of drug substitution, and conjugation methods were developed that allowed for isomeric homogeneities as high as $60-90 \%$. The in vitro and in vivo properties of these conjugates are also described.

\section{Materials and Methods}

\section{Materials}

cAC10, vcMMAE, and cAC10 with $8 \mathrm{MMAE} / \mathrm{mAb}$ (E8) were prepared as previously described (17,22). DTT, DTPA, and 4,4'-dithiodipyridine were obtained from Sigma-Aldrich (St. Louis, MO). EDTA and sodium chloride were obtained from Cambrex (Rockland, ME). Sodium borate, sodium phosphate, and citric acid were obtained from Mallinckrodt (Phillipsburg, NJ). DTNB was obtained from Pierce (Rockford, IL). TCEP and aminoethanethiol were obtained from Acros (Morris Plains, NJ). Cysteine was obtained from Alfa Aesar (Ward Hill, MA).

\section{Preparation of ADCs}

cAC10-vcMMAE with an average of $4 \mathrm{MMAE} / \mathrm{mAb}$, referred to as E4 mixture, was prepared as follows. Methods A and D were used to make cAC10-vcMMAE with $2 \mathrm{MMAE} / \mathrm{mAb}$, referred to as E2 mixture, with the indicated substitutions.

\section{Method A: Limited DTT Reduction}

cAC10 was treated with 3.25 molar equivalents of DTT ( 2.25 molar equivalents for E2 mixture) in $0.025 \mathrm{M}$ sodium borate $\mathrm{pH} 8,0.025 \mathrm{M} \mathrm{NaCl}, 1 \mathrm{mM}$ DTPA for $2 \mathrm{~h}$ at $37^{\circ} \mathrm{C}$. The excess DTT was purified away from the partially reduced cAC10 in the following manner. The mixture was first diluted 5 fold with water and applied to a hydroxyapatite column (Macroprep ceramic type I $40 \mu \mathrm{m}$, BioRad, Hercules, CA) at a flow rate of $10 \mathrm{~mL} / \mathrm{min}$. The column size was $1 \mathrm{~mL}$ per $10 \mathrm{mg}$ of cAC10. The column was previously equilibrated with 5 column volumes of 0.5 $\mathrm{M}$ sodium phosphate $\mathrm{pH} 7,10 \mathrm{mM} \mathrm{NaCl}$ and 5 column volumes of $10 \mathrm{mM}$ sodium phosphate $\mathrm{pH} 7,10 \mathrm{mM} \mathrm{NaCl}$. Following application, the column was washed with 5 column volumes

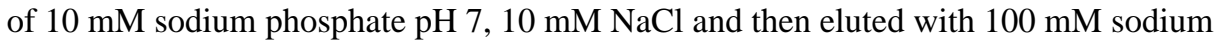
phosphate $\mathrm{pH} \mathrm{7,10} \mathrm{mM} \mathrm{NaCl}$. DTPA was added to $1 \mathrm{mM}$ following elution. The protein 
concentration was quantified using an absorbance value of 1.58 at $280 \mathrm{~nm}$ for a $1.0 \mathrm{mg} / \mathrm{mL}$ solution, and the molar concentration determined using a molecular weight of $148,449 \mathrm{~g} / \mathrm{mol}$. The concentration of mAb-cysteine thiols produced was determined by titrating with DTNB, typically resulting in 4.0 to 4.5 thiols $/ \mathrm{mAb}$ when 3.25 molar equivalents of DTT were used.

Partially reduced cAC10 was alkylated with 1.1 molar equivalents of vcMMAE/mAb-cysteine thiol. The alkylation reaction was performed at $0{ }^{\circ} \mathrm{C}$ for $30 \mathrm{~min}$. Cysteine $(1 \mathrm{mM}$ final) was used to quench any unreacted, excess vcMMAE. cAC10-vcMMAE was purified by hydroxyapatite chromatography as described above. Following elution, the buffer was changed to phosphate buffered saline (Invitrogen, Carlsbad, CA) using Amicon (Millipore, Bedford, MA) Ultrafree $30 \mathrm{~K}$ cutoff spin concentration devices. The protein concentration was quantified using an absorbance value of 1.62 at $280 \mathrm{~nm}$ for a $1.0 \mathrm{mg} / \mathrm{mL}$ solution.

\section{Method B: Limited TCEP Reduction}

cAC10 was treated with 2.75 molar equivalents of TCEP in $0.025 \mathrm{M}$ sodium borate $\mathrm{pH} 8,0.025$ $\mathrm{M} \mathrm{NaCl}, 1 \mathrm{mM}$ DTPA for $2 \mathrm{~h}$ at $37^{\circ} \mathrm{C}$. Without purification, the mixture was then cooled to $0{ }^{\circ} \mathrm{C}$ and partially reduced cAC10 alkylated with vcMMAE as described above. cAC10vcMMAE was purified using PD-10 columns (Amersham Biosciences, Piscataway, NJ) equilibrated with phosphate buffered saline.

\section{Method C: Reduction of cAC10 with Aminoethanethiol}

cAC10 was reduced with aminoethanethiol as previously described for gamma globulin (23). The reduced mAb was alkylated with vcMMAE as described above.

\section{Method D: DTNB Reoxidation of Fully Reduced cAC10}

cAC10 was treated with a large excess $(10 \mathrm{mM})$ of DTT in $0.025 \mathrm{M}$ sodium borate $\mathrm{pH} 8,0.025$ $\mathrm{M} \mathrm{NaCl}, 1 \mathrm{mM}$ DTPA for $1 \mathrm{~h}$ at $37^{\circ} \mathrm{C}$ and purified by hydroxyapatite chromatography as described above. The fully reduced cAC10 was cooled to $0{ }^{\circ} \mathrm{C}$ and then treated with 2.0 equivalents of DTNB (3.0 for E2 mixture) or 4,4'-dipyridyldithiol (from $10 \mathrm{mM}$ stock solutions) with rapid mixing. This mixture was incubated at $0{ }^{\circ} \mathrm{C}$ for $20 \mathrm{~min}$. Without further purification, partially reoxidized cAC10 was alkylated with vcMMAE as previously described and the resulting conjugate was purified by hydroxyapatite chromatography as described above.

\section{cAC10 Reduction Time Course}

cAC10 was reduced with 3.0 equivalents of DTT in $50 \mathrm{mM}$ sodium phosphate $\mathrm{pH} 7.5$ and 5 mM EDTA at $37^{\circ} \mathrm{C}$. At various times, samples were removed, quenched with an equal volume of ice-cold $200 \mathrm{mM}$ sodium citrate $\mathrm{pH}$ 5, and purified using PD-10 columns equilibrated with phosphate buffered saline containing $5 \mathrm{mM}$ EDTA. Reduced cAC10 was treated with vcMMAE as previously described and purified using PD-10 columns equilibrated with phosphate buffered saline.

\section{Purification of E2, E4, and E6 by HIC}

cAC10-vcMMAE was purified by HIC as previously described to yield ADCs with exactly 2 , 4, or $6 \mathrm{MMAE} / \mathrm{mAb}$ (referred to as E2, E4, and E6, respectively) (21). Briefly, $\mathrm{NaCl}$ was added to cAC10-vcMMAE to give a final concentration of $2.0 \mathrm{M}$ and this mixture applied to a phenyl $\mathrm{HIC}$ column. E2, E4, and E6 were eluted using step gradients of decreasing $\mathrm{NaCl}$ concentration. These purified fractions were analyzed by HIC-HPLC to determine drug loading purity as previously described $(21,24)$. HIC peaks corresponding to E2, E4, or E6 were identified as previously described: $\mathrm{cAC} 10$ and vcMMAE have distinct absorbance maxima $\left(\lambda_{\max }=280\right.$ and $248 \mathrm{~nm}$, respectively) and overlaying the UV spectra of these peaks yields A248/280 ratios 
that increase with drug loading $(21,24)$. The HIC-HPLC method was also used to isolate small amounts of E2, E4, and E6.

\section{Characterization of ADCs}

The drug loading was estimated using the molar extinction coefficients at 248 and $280 \mathrm{~nm}$ of the $\mathrm{mAb}\left(9.413 \times 10^{4}\right.$ and $2.3415 \times 10^{5} \mathrm{M}^{-1} \mathrm{~cm}^{-1}$, respectively $)$ and drug $\left(1.5 \times 10^{3}\right.$ and 1.59 $\times 10^{4} \mathrm{M}^{-1} \mathrm{~cm}^{-1}$, respectively) as previously described $(21,24)$. Size-exclusion HPLC and $\mathrm{C}_{12}$ reversed-phase HPLC were used as previously described (17) to determine the amount of aggregate and free vcMMAE, respectively, present in the ADCs.

\section{Analysis of ADCs by Capillary Electrophoresis}

The ADCs were analyzed under denaturing but non-reducing conditions using an Agilent Bioanalyzer (Palo Alto, CA). A protein 200 chip was used under denaturing but non-reducing conditions as described by the manufacturer. Briefly, $4 \mu \mathrm{L}$ of $1 \mathrm{mg} / \mathrm{mL}$ cAC10-vcMMAE was mixed with $2 \mu \mathrm{L}$ of non-reducing loading buffer and heated to $100{ }^{\circ} \mathrm{C}$ for $5 \mathrm{~min}$. Water ( 84 $\mu \mathrm{L}$ ) was added and $6 \mu \mathrm{L}$ of this mixture was loaded into each well of the chip. The molecular weights of peaks were determined using the molecular weight ladder provided and run concurrently, allowing assignment of L, H, HL, HH, HHL, and LHHL. Unconjugated cAC10 confirmed the assignment of LHHL, while E8 confirmed the assignment of $\mathrm{L}$ and $\mathrm{H}$.

\section{Analysis of ADCs by Reversed-Phase HPLC}

ADCs were analyzed under denaturing and reducing conditions using a $2.1 \times 150 \mathrm{~mm}, 8 \mu$, 1000 Å PLRP-S column (Polymer Laboratories, Amherst, MA). The flow rate was $1 \mathrm{~mL} / \mathrm{min}$ and the column temperature was $80{ }^{\circ} \mathrm{C}$. Solvent A was $0.05 \%$ trifluoroacetic acid in water and solvent $\mathrm{B}$ was $0.04 \%$ trifluoroacetic acid in acetonitrile. The method consisted of the following: Isocratic $25 \%$ B for $3 \mathrm{~min}$, a 25 -min linear gradient to $50 \% \mathrm{~B}$, a 2-min linear gradient to $95 \%$ $\mathrm{B}$, a 1-min linear gradient to $25 \% \mathrm{~B}$, and isocratic $25 \% \mathrm{~B}$ for $2 \mathrm{~min}$. Injections were 10-20 $\mu \mathrm{L}$ of $1 \mathrm{mg} / \mathrm{mL}$ cAC 10 -vcMMAE previously reduced with $20 \mathrm{mM}$ DTT at $37^{\circ} \mathrm{C}$ for $15 \mathrm{~min}$ to cleave the remaining interchain disulfides. The number of moles and mole fraction of each chain was determined using the following molar extinction coefficients: $30,160 \mathrm{M}^{-1} \mathrm{~cm}^{-1}$

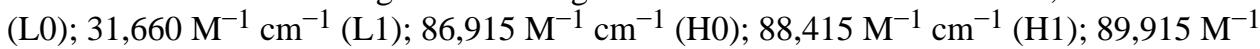
$\mathrm{cm}^{-1}(\mathrm{H} 2) ; 91,415 \mathrm{M}^{-1} \mathrm{~cm}^{-1}$ (H3). Peak assignments were made with unconjugated cAC10 (L0 and $\mathrm{H} 0$ ) and $\mathrm{E} 8(\mathrm{~L} 1$ and $\mathrm{H} 3$ ). $\mathrm{H} 1$ and $\mathrm{H} 2$ were assigned by their elution time (eluting between $\mathrm{H} 0$ and $\mathrm{H} 3$ ) and $\mathrm{UV}$ spectra (the A248/280 ratio increases with drug loading).

\section{Determination of Isomeric Distribution}

The isomeric distribution for E2 and E6 was determined using solely reversed-phase HPLC data from the mole fractions determined above. For E2 isomer A, the mole fraction of L0 and $\mathrm{H} 1$ are equal, while for $\mathrm{E} 2$ isomer $\mathrm{B}$, the mole fraction of $\mathrm{L} 0, \mathrm{~L} 1, \mathrm{H} 0$, and $\mathrm{H} 1$ are equal. With the sum of the mole percent of L0, L1, H0, and $\mathrm{H} 1$ set to $100 \%$, the percent isomer B can be determined as follows:

$$
\% \mathrm{~B}=2(\% \mathrm{~L} 1)+2(\% \mathrm{H} 0)
$$

where $\% \mathrm{~L} 1=$ mole fraction of $\mathrm{L} 1$ and $\% \mathrm{H} 0=$ mole fraction $\mathrm{H} 0$. The percent of isomer $\mathrm{A}$ is assumed to be $100-\% \mathrm{~B}$.

Similarly, for E6 isomer A, the mole fraction of $\mathrm{L} 1$ and $\mathrm{H} 2$ are equal, while for E6 isomer B, the mole fractions of $\mathrm{L} 0, \mathrm{~L} 1, \mathrm{H} 2$, and $\mathrm{H} 3$ are equal. With the sum of the mole percent of $\mathrm{L} 0$, $\mathrm{L} 1, \mathrm{H} 2$, and $\mathrm{H} 3$ set to $100 \%$, the percent isomer $\mathrm{B}$ can be determined as follows:

$$
\% \mathrm{~B}=2(\% \mathrm{LO})+2(\% \mathrm{H} 3)
$$


where $\% \mathrm{~L} 0=$ mole fraction of $\mathrm{L} 0$ and $\% \mathrm{H} 3=$ mole fraction $\mathrm{H} 3$. The percent of isomer $\mathrm{A}$ is assumed to be $100-\% \mathrm{~B}$.

Due to more possible isomers, the percentages of the $\mathrm{E} 4$ isomers cannot be obtained solely from the reversed-phase HPLC data because no isomer gives a unique light and heavy chain pattern. The amount of E4 isomer A was first determined from capillary electrophoresis data using the HHL, $\mathrm{HH}$, and HL peak areas as follows:

$$
\% \mathrm{~A}=\frac{\frac{\mathrm{HHL}}{124720.8}}{\frac{\mathrm{HHL}}{124720.8}+\frac{\mathrm{HH}}{100992.6}+\frac{\mathrm{HL}}{2^{*} 74224.5}}
$$

With the sum of the mole percent of L0, L1, H1, and $\mathrm{H} 2$ set to $100 \%$, reversed-phase HPLC data was then used to solve for the remaining contribution of $\mathrm{E} 4$ isomers $\mathrm{B}$ and $\mathrm{C}$ using the following formulas:

$$
\begin{aligned}
& \% \mathrm{~B}=\% \mathrm{H} 1+\% \mathrm{~L} 1-0.5(\% \mathrm{~A}) \\
& \% \mathrm{C}=\% \mathrm{H} 2+\% \mathrm{~L} 0-0.5(\% \mathrm{~A})
\end{aligned}
$$

where $\% \mathrm{H} 1=$ mole fraction of $\mathrm{H} 1, \% \mathrm{~L} 1=$ mole fraction $\mathrm{L} 1, \% \mathrm{H} 2=$ mole fraction $\mathrm{H} 2$, and $\%$ $\mathrm{L} 0=$ mole fraction $\mathrm{L} 0$.

\section{Simulations}

The simulated partial reduction of cAC10 was carried out using a series of coupled ordinary differential equations (25) with an integration algorithm (4th order Runge-Kutta) implemented as a VBA function in Excel (Microsoft Corp., Redmond, WA). The rate constants for reduction of heavy-light and heavy-heavy disulfides were equal. The simulation assumes 2 equivalent heavy-light and 2 equivalent heavy-heavy disulfides per $\mathrm{mAb}$, with the relative rate constants for the reduction of the first and second of these equivalent disulfides being 2:1 due to the 2:1 stoichiometry (for example, when the first heavy-light disulfide is reduced, there are 2 heavylight disulfides present, whereas when the second heavy-light disulfide is reduced, there is only 1 heavy-light disulfide present). The simulation used a concentration of reductant sufficient to reduce an average of 2 disulfides per $\mathrm{mAb}$. Figures $\mathrm{S} 1$ and $\mathrm{S} 2$ show the mechanism and the differential equations used in the simulation.

\section{Binding Studies}

ADCs were labeled with 36 molar equivalents of europium N1-isothiocyanate (Perkin Elmer Biosciences, Wellesley MA) overnight at $4{ }^{\circ} \mathrm{C}$ in $50 \mathrm{mM} \mathrm{Na}_{2} \mathrm{CO}_{3}$, $\mathrm{pH}$ 9.0. Small molecular weight agents were removed by gel filtration on PD-10 columns equilibrated with Tris buffered saline (TBS, $50 \mathrm{mM}$ Tris $\mathrm{HCl}, \mathrm{pH} 8.0,150 \mathrm{mM} \mathrm{NaCl}$ ) followed by dialysis overnight in TBS at $4{ }^{\circ} \mathrm{C}$. Conjugate concentration was determined by UV absorbance. Analysis of the europium content (by release into DELFIA enhancement solution, Perkin Elmer) indicated that there were 5- 7 europium labels $/ \mathrm{mAb}$. Karpas 299 ALCL cells $\left(100 \mu \mathrm{L} / \mathrm{well}\right.$ at $1 \times 10^{6} / \mathrm{mL}$ in TBS $+0.5 \%$ FBS, $10 \mu \mathrm{M}$ EDTA) were incubated with increasing dilutions of labeled ADC or parental cAC10 for $1 \mathrm{~h}$ at $4{ }^{\circ} \mathrm{C}$ on a plate rocker. Following incubation, the cells were washed 3 times in TBS, resuspended in $200 \mu \mathrm{L}$ of enhancement solution, transferred to DELFIA yellow sided plates and incubated on an orbital shaker for $5 \mathrm{~min}$ at room temperature. Fluorescence was monitored using a Fusion HTS microplate reader (Perkin Elmer) using the time-resolved fluorescence mode using an excitation wavelength of $335 \mathrm{~nm}$ and emission wavelength set at $620 \mathrm{~nm}$. The time delay between excitation and emission was $400 \mu \mathrm{sec}$. After reading, data were reduced and binding analyzed using the one-site binding model in GraphPad Prism version 4.01 for Windows (GraphPad Software, San Diego CA). Binding curves experiments were performed a minimum of three times to ensure accuracy. 


\section{Cytotoxicity Assays}

The experiments were performed as previously described (17). Briefly, Karpas 299 cells were treated with ADCs for $92 \mathrm{~h}$ before adding resazurin and incubating an additional $4 \mathrm{~h}$. Dye reduction was measured using a fluorescent plate reader.

\section{In Vivo Studies}

In vivo efficacy of ADCs in xenograft models of human $\mathrm{CD} 30^{+}$tumors in SCID mice and the maximum tolerated dose of ADCs in BALB/c mice were performed as previously described (21). Briefly, subcutaneous Karpas-299 tumors were grown in C.B.-17 SCID mice, with the test articles administered when tumors reached approximately $100 \mathrm{~mm}^{3}$ (length $\times$ width $\left.{ }^{2}\right) / 2$. Animals (7-10/group) were injected iv with the ADCs at the doses indicated. Animals were considered cured if they were tumor free 101 days post tumor implant. Groups were compared for statistical significance by pair wise treatment of Kaplan-Meier analysis using GraphPad Prism version 4.01. To evaluate the MTD, BALB/c mice (parent strain of the C.B. -17 SCID) were administered with ADCs. Animal weights were measured and clinical observations were recorded over a 14 day period. The MTD was assigned as the highest single dose administered to an animal that did not result in weight loss $\geq 20 \%$ or lead to any signs of distress.

\section{Results}

\section{Reduction Methods}

Two general strategies were used to prepare ADCs with an average of $4 \mathrm{MMAE} / \mathrm{mAb}$ (referred to as $\mathrm{E} 4$ mixture). The first involved limited reduction of the interchain disulfides of the chimeric $\mathrm{mAb}$ cAC10, an IgG1, followed by alkylation with maleimidocaproyl-val-cit-PABAMMAE (vcMMAE). This two-step process led to the formation of cAC10-vcMMAE. About 3.25 and 2.75 molar equivalents of the strong reducing agents DTT and TCEP, respectively, were sufficient to cleave 2 interchain disulfide bonds, yielding an average of $4 \mathrm{cAC} 10$ cysteines $/ \mathrm{mAb}$. Partial reduction of cAC10 could also be accomplished using the weaker reducing agent aminoethanethiol, which at $\mathrm{pH} 5$ requires about 500 molar equivalents to yield 4 cAC10 cysteines/mAb. Unlike the thiol-based reducing agents, phosphines such as TCEP react poorly with maleimides, and the excess reducing agent does not have to be removed before adding vcMMAE.

A second general strategy for controlled drug substitution involves fully reducing cAC10 with DTT and then partially reoxidizing the resulting thiol groups with DTNB. This reoxidation process is very efficient, requiring 2.0 equivalents of DTNB to reoxidize $8 \mathrm{mAb}$ cysteines back to 4 . Treatment of this reoxidized $\mathrm{mAb}$ with a thiol such as cysteine does not liberate any bound thionitrobenzoic (TNB) acid, suggesting that the reoxidized cysteines are in the form of $\mathrm{mAb}$ disulfides rather than mixed TNB-cysteine disulfides. The remaining mAb cysteines can then be conjugated to vcMMAE.

\section{Quantification of Drug Loading Levels}

Figure 2 shows the normalized percentages of the even drug loaded species prepared by DTT partial reduction, TCEP partial reduction, and partial DTNB reoxidation as determined by HICHPLC. The DTNB partial reoxidation method yields a slightly higher percentage of E4 (42\%) than the partial reduction methods ( $32 \%$ for DTT and $36 \%$ for TCEP). This comes at the expense of mainly E6 and E8, which total about 37\% for DTT partial reduction and 34\% for TCEP partial reduction, while only $27 \%$ for DTNB partial reoxidation. 


\section{Isomeric Populations}

To determine the isomeric population of each of the drug loaded species, cAC10-vcMMAE prepared with various methods was first separated by preparative HIC, yielding E2, E4, and E6. The purities of these materials, with respect to their drug loading levels, was at least $95 \%$ as determined by analytical HIC-HPLC (21). The HIC-purified materials were then subjected a combination of reducing and non-reducing methods to assign the distribution of the drugs on the mAb. Reducing and denaturing reversed-phase HPLC was used to separate and quantify various light and heavy chain species. In this method, pretreatment of the ADC with an excess of DTT breaks the remaining interchain disulfides and allows separation of light chain with 0 or 1 drugs (L0 and L1) from heavy chain with $0,1,2$, or 3 drugs (H0, H1, H2, and H3) (Figure 3 , A-D). A second form of analysis involved non-reducing and denaturing capillary electrophoresis, allowing for the separation of 6 potential mAb species: L, H, HL, HH, HHL, and LHHL (Figure 3, E-H). Figure 4 shows the possible isomers of E2, E4, and E6 and the expected distribution of $\mathrm{mAb}$ fragments under denaturing conditions in both reducing and nonreducing environments. The isomeric populations of E2 and E6 were readily determined by reversed-phase HPLC since each isomer yields a unique fragment pattern. For example, isomer E2B yields $\mathrm{L} 1$ and $\mathrm{H} 0$ under denaturing and reducing conditions, while E2A yields $\mathrm{L} 0$ and H1. Under denaturing and non-reducing conditions, isomer E2A yields LHHL, while E2B yields $\mathrm{L}$ and HHL. For E4, the three potential isomers do not yield unique fragment patterns on reversed-phase HPLC or capillary electrophoresis alone, requiring that the combined results must be used to assign the isomeric population.

Figure 5 shows the percent composition for each of these isomers. Both partial reduction methods gave similar isomer populations. However, for E2, DTT partial reduction and DTNB partial reoxidation gave contrasting isomeric populations: the former method yielded $92 \%$ E2B, while the latter method yielded 77\% E2A. Similarly, E4B is the predominant isomer for DTT partial reduction (59\%), while E4C is the predominant isomer for DTNB partial reoxidation $(75 \%)$. The chemistry used to prepare the reduced antibody plays a significant role in the location of the drugs in the resulting conjugate. Interestingly, both methods yield E6B as the predominant E6 isomer in very high yields $(96-98 \%)$. There are also smaller differences in the distribution of isomers observed from the DTT and TCEP partial reduction methods, the largest of which can be seen in isomers E4B and E4C. DTT partial reduction yields about 2:1 E4B to E4C, while TCEP partial reduction yields about 1:1.

\section{Simulated Partial Reduction}

The observed drug loading levels and isomeric populations are significantly different for the partial reduction and partial reoxidation methods, which may indicate that there is some degree of selectivity in reducing and oxidizing $\mathrm{mAb}$ heavy-light and heavy-heavy disulfides. A simulation of cAC10 partial reduction was performed in which disulfides were allowed to be randomly reduced under conditions where the rate constants for the reduction of heavy-light and heavy-heavy disulfides were equal. Figure 6a shows the simulated drug loading levels for E0, E2, E4, E6, and E8 and the percent difference between these simulated values and the HICHPLC data for DTT and TCEP partial reduction. The percent difference varies systematically, in that the experimentally determined amounts of E0 and E8 were significantly larger than the simulated values, while the amounts of E2, E4, and E6 were slightly less than the simulated values. Figure $6 \mathrm{~b}$ shows the simulated isomer populations and the percent difference between the simulation and the values determined from reversed-phase HPLC and capillary electrophoresis. The experimentally determined isomer abundances were as much as $250 \%$ more and up to nearly $100 \%$ less than the simulated values. No experimentally determined isomer abundance was within $75 \%$ of the simulated values. These results strongly suggest that the reduction is not a random process and the rate constants for reduction of individual cAC10 disulfides are widely different. 


\section{DTT Reduction Time Course}

Because of the long reduction time necessary to form partially reduced cAC10 with DTT, the isomeric population could change during the reduction reaction and using the end point of the reaction would not be representative of the overall reduction process. To address this, the isomeric compositions of the product ADCs were determined at various time intervals after the addition of the reducing agent. Reduction times of 10 to 120 min yielded drug loadings of 1.3 to 3.9 drugs $/ \mathrm{mAb}$. Table 1 shows that the isomeric composition does not change over the course of the reduction reaction. Thus, the reduction process is under kinetic rather than thermodynamic control, and using the end point of the reaction is appropriate.

\section{Binding to CD30 Positive Cells}

cAC10-vcMMAE conjugates were tested for their abilities to bind to CD30 positive Karpas 299 Anaplastic Large Cell Lymphoma cells. Table 2 shows that unmodified cAC10 and ADCs with 2 drugs $/ \mathrm{mAb}$ bound with similar affinities, 2.0 to $3.6 \mathrm{nM}$. ADCs with 4 and 8 drugs $/ \mathrm{mAb}$ bound slightly weaker, 6.5 to $7.8 \mathrm{nM}$. The chemistry used to prepare the ADCs did not significantly influence the ability of the ADCs to bind to the cells.

\section{In Vitro Cytotoxicity}

Mixtures with an average of 2 and 4 drugs/mAb as well as HIC purified E2 and E4 were investigated for their in vitro activities on Karpas 299 cells. Table 2 shows the ADCs with 2 and 4 drugs $/ \mathrm{mAb}$ have $\mathrm{IC}_{50}$ values from 11.4 to $13.8 \mathrm{ng} / \mathrm{mL}$ and 3.4 to $5.0 \mathrm{ng} / \mathrm{mL}$, respectively. E8 gave the lowest value of $2.7 \mathrm{ng} / \mathrm{mL}$ and unconjugated cAC10 showed no effect. Thus, cytotoxic activity increases with increased drug substitution, but is not dependent on ADC isomeric composition.

\section{In Vivo Toxicity and Therapeutic Efficacy}

MTD values in immunocompetent BALB/c mice were determined by iv ADC injections. As previously described, the MTD of E8 was $50 \mathrm{mg} / \mathrm{kg}$ (21). Significantly more of the ADCs could be administered with lower drug loading. The best tolerated ADC was E2 made by DTT partial reduction, which was devoid of toxicity at $250 \mathrm{mg} / \mathrm{kg}$, the highest dose tested. The MTD of E4 prepared by the DTNB partial reoxidation method was $120 \mathrm{mg} / \mathrm{kg}$, which was slightly less toxic than the corresponding E4 ADC prepared by DTT partial reduction (MTD of 100 $\mathrm{mg} / \mathrm{kg}$ ). Consistent with in vitro cytotoxicity, the number of drugs $/ \mathrm{mAb}$ had a much more pronounced influence on toxicity than the placement of the drug on the mAb.

Therapeutic efficacy experiments were performed in SCID mice with subcutaneous Karpas 299 tumors. Single doses of the ADCs were given 11 (E4) or 14 (E2) days after tumor implant, when the tumors had reached approximately $100 \mathrm{~mm}^{3}$. Figure 7a shows that for E2 made by DTT partial reduction and DTNB partial reoxidation methods, $1.0 \mathrm{mg} / \mathrm{kg}$ of ADC both gave delays in tumor growth. Although E2 made by DTT partial reduction gave 5 cures out of 7 while E2 made by DTNB partial reoxidation provided 1 cure out of 7, Kaplan-Meier analysis for survival showed that there was not a statistical difference between these 2 chemistries $(\mathrm{P}=0.08)$. However, since the $\mathrm{P}$ value is trending towards significance $(0.05<\mathrm{P}<0.1)$, further studies are required with larger group sizes to determine if these chemistries yield differences in efficacy. The E4 ADCs which were made by DTT partial reduction, TCEP partial reduction, and DTNB partial reoxidation gave delays in tumor growth at both 0.5 and $1.0 \mathrm{mg} / \mathrm{kg}$ (Figure $7 b$ ). Nearly identical cure rates were obtained at $1 \mathrm{mg} / \mathrm{kg}$ for all 3 production methods ( 8 to 10 cures out of 10), suggesting that the production methods yielded ADCs with similar efficacies $(\mathrm{P}=0.15$ for $\mathrm{E} 4$ made by TCEP partial reduction compared to $\mathrm{E} 4$ made by either DTT partial reduction or DTNB partial reoxidation). 


\section{Discussion}

We have demonstrated for the first time that IgG1 interchain disulfide bonds can be distinguished by chemical reduction and oxidization methods. This was made possible using the drug MMAE to fix the disulfide bonding pattern by alkylating free cysteines, allowing separation of the drug loading levels by HIC, and facilitating the analysis of the isomeric populations.

As shown in Figure 3, the production method significantly affects the location of the drugs, suggesting that the $\mathrm{mAb}$ disulfides can be selectively reduced. Partial DTT reduction yields predominantly isomer E2B, which results from reduction of one of the heavy-light chain disulfides. Conjugates consisting of E4 were comprised mainly of isomer E4B, which results from the reduction of both heavy-light chain disulfides. The main E6 species detected was isomer E6B, which results from reduction of both heavy-heavy chain disulfides and one heavylight chain disulfide, while isomers with one heavy-heavy chain disulfide reduced were in the extreme minority. On the other hand, partial DTNB reoxidation yields almost the opposite result for $\mathrm{E} 2$ and $\mathrm{E} 4$ isomers, with predominantly isomers $\mathrm{E} 2 \mathrm{~A}$ and $\mathrm{E} 4 \mathrm{C}$, where one heavyheavy chain disulfide is intact, and the same result for E6. We have observed qualitatively similar preferences of the isomer populations from partial reduction and partial reoxidiation of the humanized anti-Her2 IgG1 Herceptin (data not shown).

Previous investigations of mAb disulfide biochemistry did not demonstrate whether there was selective reduction of particular $\mathrm{mAb}$ interchain disulfides, in part because of the inability to fractionate the reduction reaction into subpopulations together with the low resolution of the analytical techniques employed. SDS-PAGE was used extensively (26-28), but this technique could not resolve and quantify the 9 possible isomers present in a mAb reduction reaction. Figure 3 shows that the E4 mixtures prepared by partial DTT reduction and partial DTNB reoxidation are difficult to distinguish, while HIC-purified E4 prepared by these chemistries are readily distinguished. In the past, analytical ultracentrifugation was also used to characterize $\mathrm{mAb}$ interchain disulfide reduction using aminoethanethiol under acidic conditions, and this data was used to suggest that exclusively heavy-heavy disulfides can be cleaved under these conditions (29-31). These data are even lower resolution than SDS-PAGE and cannot provide molecular characterization of the generated species. Our data are in contrast to this report, since partial reduction of $\mathrm{cAC} 10$ by aminoethanethiol at $\mathrm{pH} 5$ results in a mixture of E4B and E4C present in nearly a 1:1 ratio (Figure 5), rather than only E4C, which would result from exclusive heavy-heavy disulfide reduction. The analytical technologies used in the previous reports (29-31) were evidently not sensitive enough to support the conclusions drawn.

The isomeric populations that result from partial DTT reduction demonstrate that IgG1 heavyheavy disulfide bond cleavage is a cooperative process. Very little of any of the isomers with one heavy-heavy disulfide bond intact are observed, even at very early time points during the reduction (Table 1). The E2 isomer formed in greater than $90 \%$ abundance (E2B) has one heavy-light disulfide bond cleaved, while the predominant E4 isomer (E4B) has both of the heavy-light chain disulfides cleaved.

The simulated partial reduction with equal rate constants for heavy-light and heavy-heavy disulfide reduction confirm that the reduction of cAC10 is not a random process. The drug loading distribution and isomer distribution are significantly different between the simulation and experimental data, suggesting that a more complex model with unequal rate constants is much more appropriate in describing the cAC10 reduction process. We are currently performing additional simulations with other models to determine the rate constants that describe cAC10 reduction. These simulations will enable us to determine the relative rate constants of reduction of the heavy-light versus heavy-heavy disulfides, as well as the rate 
constants of reduction of the first versus the second heavy-light and heavy-heavy disulfides. Simulations may also be able to explain the small observed differences between DTT and TCEP partial reduction, with these two reducing agents potentially having different absolute reducing strengths as well as differences in their rate constants for reduction of individual disulfides.

Inspection of X-ray crystal structures (PDB structures include 1HZH and 1IGT) $(20,32,33)$ show the region around these heavy-heavy disulfides to be highly flexible, and electron density is often absent. These disulfide bonds may be responsible for any local structure, and release of one may open up this region, allowing the second to be more exposed to solvent and reducing agents. The cleavage of these disulfides is not expected to cause large changes in the overall protein structure (20).

The partial DTNB reoxidation process preferentially re-forms the heavy-light chain disulfides, as was seen previously for air reoxidation (26). The E6 isomer formed in greater than $90 \%$ abundance (E6B) has one heavy-light disulfide, and the predominant E4 isomer (E4C) has both heavy-light disulfides. Unlike DTT reduction, reformation of the heavy-heavy disulfides does not appear to be cooperative, in that the predominant E2 isomer has just one heavy-heavy disulfide. Reformation of heavy-heavy disulfides appears to be merely kinetically slower than the heavy-light disulfides. If cleavage of the heavy-heavy disulfides releases the local structure and the previously paired cysteines can move away from each other, the kinetics of heavyheavy disulfide bond formation will be slow. The heavy-light disulfide is probably not responsible for local structure or relative positioning of the heavy and light chains, and the unpaired cysteines will remain in close proximity and proper orientation for disulfide bond formation.

The chemistries described herein enable the generation of highly site-specific conjugates. For cAC10-vcMMAE, the effect of the location of the drugs on biological activity is modest, with the only significant difference being the MTD values of E4 made by DTNB partial reoxidation being higher than E4 made by DTT partial reduction. It is likely that other biologically interesting molecules such as fluorophores and fluorescence resonance energy transfer reagents may benefit from site-specific conjugation, and this is an area that we are currently investigating. The ability to control the molecular composition in ADCs by chemical means complements recombinant strategies, and allows for the generation of well defined ADCs with potent biological activities.

\section{Supplementary Material}

Refer to Web version on PubMed Central for supplementary material.

\section{Acknowledgement}

We thank Angela Merges, Sarah Hall, and Jamie Andreyka for technical assistance. This work was supported in part by Grant R44 CA088583-02A1 from the National Institutes of Health.

\section{Abbreviations}

$\mathrm{ADC}, \mathrm{mAb}$ drug conjugate

DTNB, 5,5'-dithiobis(2-nitrobenzoic acid)

DTPA, diethyeletriaminepentaacetic acid

DTT, dithiothreitol

E0, E2, E4, E6, E8, cAC10, 0, 2, 4, 6, 8 MMAE per mAb, respectively

$\mathrm{H} 0, \mathrm{H} 1, \mathrm{H} 2, \mathrm{H} 3$, heavy chain, $0,1,2,3 \mathrm{MMAE}$, respectively

HIC, hydrophobic interaction chromatography

L0, L1, light chain, 0, 1 MMAE, respectively 
mAb, monoclonal antibody

MMAE, monomethyl auristatin E

MTD, maximum tolerated dose

TCEP, tris(2-carboxyethyl)phosphine

vcMMAE, maleimidocaproyl-valine-citruline-PABA-MMAE

\section{References}

1. Senter PD, Springer CJ. Selective activation of anticancer prodrugs by monoclonal antibody-enzyme conjugates. Adv Drug Deliv Rev 2001;53:247-64. [PubMed: 11744170]

2. Sharkey RM, Goldenberg DM. Perspectives on cancer therapy with radiolabeled monoclonal antibodies. J Nucl Med 2005;46(Suppl 1):115S-27S. [PubMed: 15653660]

3. Trail PA, King HD, Dubowchik GM. Monoclonal antibody drug immunoconjugates for targeted treatment of cancer. Cancer Immunol Immunother 2003;52:328-37. [PubMed: 12700948]

4. Bohdiewicz PJ. Indium-111 satumomab pendetide: the first FDA-approved monoclonal antibody for tumor imaging. J Nucl Med Technol 1998;26:155-63. [PubMed: 9755434]quiz 170-1

5. Van de Wiele C, Revets H, Mertens N. Radioimmunoimaging. Advances and prospects. Q J Nucl Med Mol Imaging 2004;48:317-25. [PubMed: 15640795]

6. Porstmann T, Kiessig ST. Enzyme immunoassay techniques. An overview. J Immunol Methods 1992;150:5-21. [PubMed: 1613258]

7. Lichlyter DJ, Grant SA, Soykan O. Development of a novel FRET immunosensor technique. Biosens Bioelectron 2003;19:219-26. [PubMed: 14611757]

8. Wisdom GB. Conjugation of antibodies to fluorescein or rhodamine. Methods Mol Biol 2005;295:1314. [PubMed: 15596893]

9. Gudmundsson BM, Young NM, Oomen RP. Characterisation of residues in antibody binding sites by chemical modification of surface-adsorbed protein combined with enzyme immunoassay. J Immunol Methods 1993;158:215-27. [PubMed: 7679132]

10. Wines BD, Easterbrook-Smith SB. Carbodiimide crosslinking of human C1q and rabbit IgG. Mol Immunol 1990;27:221-6. [PubMed: 2342486]

11. Casey JL, Coley AM, Tilley LM, Foley M. Green fluorescent antibodies: novel in vitro tools. Protein Eng 2000;13:445-52. [PubMed: 10877856]

12. Hayashi N, Kipriyanov S, Fuchs P, Welschof M, Dorsam H, Little M. A single expression system for the display, purification and conjugation of single-chain antibodies. Gene 1995;160:129-30. [PubMed: 7628706]

13. Schneider P. Production of recombinant TRAIL and TRAIL receptor: Fc chimeric proteins. Methods Enzymol 2000;322:325-45. [PubMed: 10914028]

14. Siemers NO, Kerr DE, Yarnold S, Stebbins MR, Vrudhula VM, Hellstrom I, Hellstrom KE, Senter PD. Construction, expression, and activities of L49-sFv-beta-lactamase, a single-chain antibody fusion protein for anticancer prodrug activation. Bioconjug Chem 1997;8:510-9. [PubMed: 9258449]

15. Rodwell JD, Alvarez VL, Lee C, Lopes AD, Goers JW, King HD, Powsner HJ, McKearn TJ. Sitespecific covalent modification of monoclonal antibodies: in vitro and in vivo evaluations. Proc Natl Acad Sci U S A 1986;83:2632-6. [PubMed: 3458222]

16. Chang IN, Lin JN, Andrade JD, Herron JN. Photoaffinity labeling of antibodies for applications in homogeneous fluoroimmunoassays. Anal Chem 1995;67:959-66. [PubMed: 7762830]

17. Doronina SO, Toki BE, Torgov MY, Mendelsohn BA, Cerveny CG, Chace DF, DeBlanc RL, Gearing RP, Bovee TD, Siegall CB, Francisco JA, Wahl AF, Meyer DL, Senter PD. Development of potent monoclonal antibody auristatin conjugates for cancer therapy. Nat Biotechnol 2003;21:778-84. [PubMed: 12778055]

18. Trail PA, Willner D, Lasch SJ, Henderson AJ, Hofstead S, Casazza AM, Firestone RA, Hellstrom I, Hellstrom KE. Cure of xenografted human carcinomas by BR96-doxorubicin immunoconjugates. Science 1993;261:212-5. [PubMed: 8327892]

19. Francisco JA, Cerveny CG, Meyer DL, Mixan BJ, Klussman K, Chace DF, Rejniak SX, Gordon KA, DeBlanc R, Toki BE, Law CL, Doronina SO, Siegall CB, Senter PD, Wahl AF. cAC10-vcMMAE, 
an anti-CD30-monomethyl auristatin E conjugate with potent and selective antitumor activity. Blood 2003;102:1458-65. [PubMed: 12714494]

20. Saphire EO, Stanfield RL, Crispin MD, Parren PW, Rudd PM, Dwek RA, Burton DR, Wilson IA. Contrasting IgG structures reveal extreme asymmetry and flexibility. J Mol Biol 2002;319:9-18. [PubMed: 12051932]

21. Hamblett KJ, Senter PD, Chace DF, Sun MM, Lenox J, Cerveny CG, Kissler KM, Bernhardt SX, Kopcha AK, Zabinski RF, Meyer DL, Francisco JA. Effects of drug loading on the antitumor activity of a monoclonal antibody drug conjugate. Clin Cancer Res 2004;10:7063-70. [PubMed: 15501986]

22. Wahl AF, Klussman K, Thompson JD, Chen JH, Francisco LV, Risdon G, Chace DF, Siegall CB, Francisco JA. The anti-CD30 monoclonal antibody SGN-30 promotes growth arrest and DNA fragmentation in vitro and affects antitumor activity in models of Hodgkin's disease. Cancer Res 2002;62:3736-42. [PubMed: 12097283]

23. Mandy WJ, Nisonoff A. Effect of Reduction of Several Disulfide Bonds on the Properties and Recombination of Univalent Fragments of Rabbit Antibody. Journal of Biological Chemistry 1963;238:206-213.

24. Sanderson RJ, Hering MA, James SF, Sun MM, Doronina SO, Siadak AW, Senter PD, Wahl AF. In vivo drug-linker stability of an anti-CD30 dipeptide-linked auristatin immunoconjugate. Clin Cancer Res 2005;11:843-52. [PubMed: 15701875]

25. Olson JS. Numerical analysis of kinetic ligand binding data. Methods Enzymol 1981;76:652-67. [PubMed: 7329282]

26. Sears DW, Beychok S. Acquisition of the covalent quaternary structure of an immunoglobulin G molecule. Theoretical reoxidation models. Biochemistry 1977;16:2026-31. [PubMed: 403937]

27. Sears DW, Mohrer J, Beychok S. Relative susceptibilities of the interchain disulfides of an immunoglobulin $\mathrm{G}$ molecule to reduction by dithiothreitol. Biochemistry 1977;16:2031-5. [PubMed: 403938]

28. Virella G, Parkhouse RM. Sensitivity to reduction of human immunoglobulin G of different heavy chain sub-classes. Immunochemistry 1973;10:213-7. [PubMed: 4199403]

29. Hermanson, G. Bioconjugate Techniques. Academic Press; San Diego: 1996.

30. Kato K, Hamaguchi Y, Fukui H, Ishikawa E. Enzyme-linked immunoassay. Conjugation of rabbit anti-(human immunoglobulin G) antibody with beta-D-galactosidase from Escherichia coli and its use for human immunoglobulin G assay. Eur J Biochem 1976;62:285-92. [PubMed: 943288]

31. Palmer JL, Nisonoff A, Vanholde KE. Dissociation of Rabbit Gamma Globulin into Subunits by Reduction and Acidification. Proc Natl Acad Sci U S A 1963;50:314-21. [PubMed: 14060650]

32. Harris LJ, Larson SB, Hasel KW, McPherson A. Refined structure of an intact IgG2a monoclonal antibody. Biochemistry 1997;36:1581-97. [PubMed: 9048542]

33. Saphire EO, Parren PW, Pantophlet R, Zwick MB, Morris GM, Rudd PM, Dwek RA, Stanfield RL, Burton DR, Wilson IA. Crystal structure of a neutralizing human IGG against HIV-1: a template for vaccine design. Science 2001;293:1155-9. [PubMed: 11498595] 


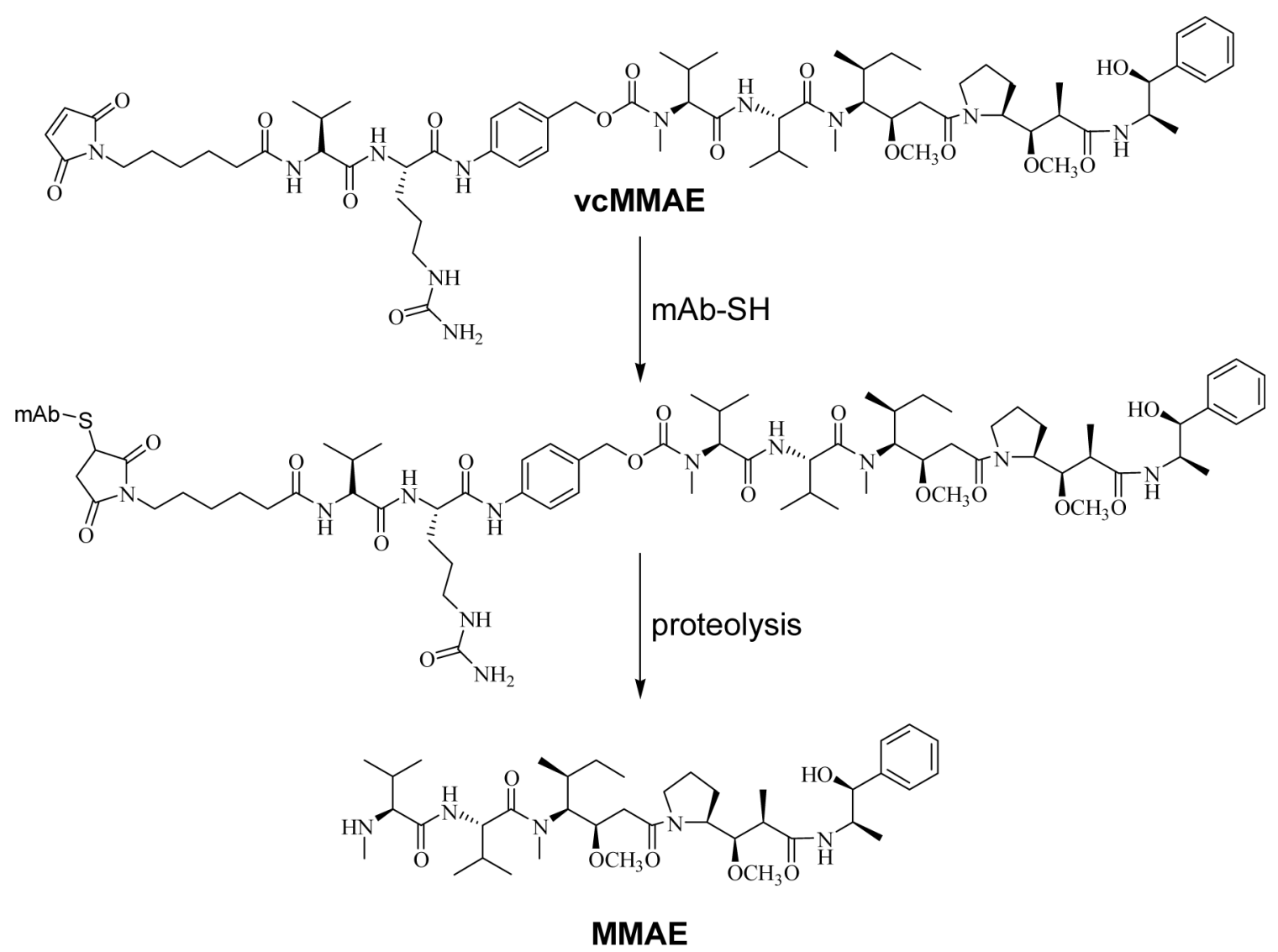

1.

Conjugation strategy. The drug-linker vcMMAE reacts with a mAb cysteine to form the ADC. The potent antimitotic agent MMAE is released from the ADC following proteolysis. As many as 8 molecules of vcMMAE can react with each $\mathrm{mAb}$ following reduction of the 4 interchain disulfides present in cAC10. 


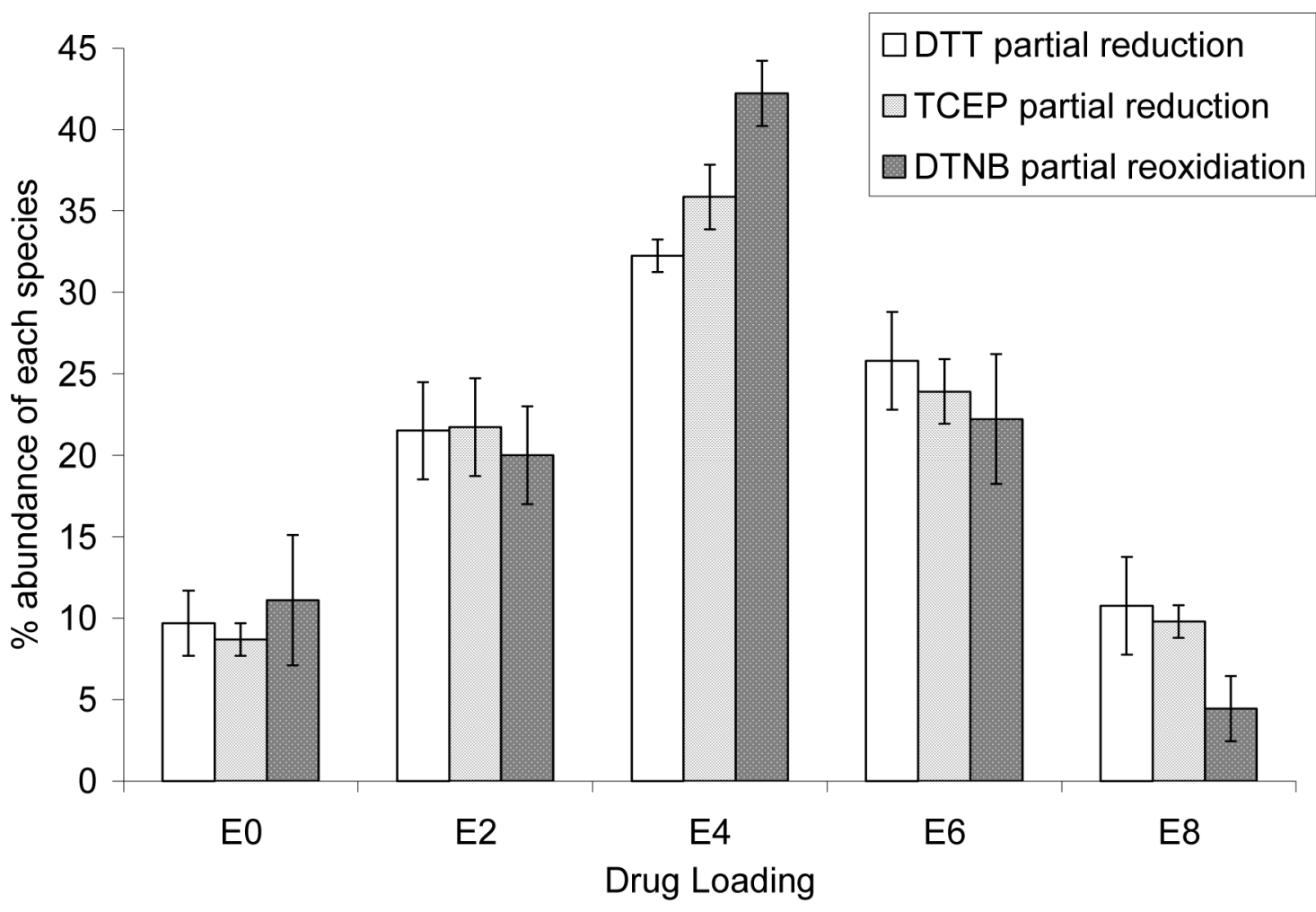

2.

Composition of E4 mixture as a function of conjugation methodology. HICHPLC chromatograms were integrated to determine the abundance of E0, E2, E4, E6, and E8 in the mixtures. Values are \pm standard deviation for 4 (DTT partial reduction), 3 (TCEP partial reduction), or 6 (DTNB partial reoxidation) separate experiments. The contributions from oddloaded species, typically less than 10\%, are not shown. The sum of E0, E2, E4, E6, and E8 was normalized to $100 \%$. The simulated reduction assumes that the rate constants for reduction of the 4 interchain disulfides are equal for a random reduction process, and the sum of E0, E2, E4, E6, and E8 equals $100 \%$. 

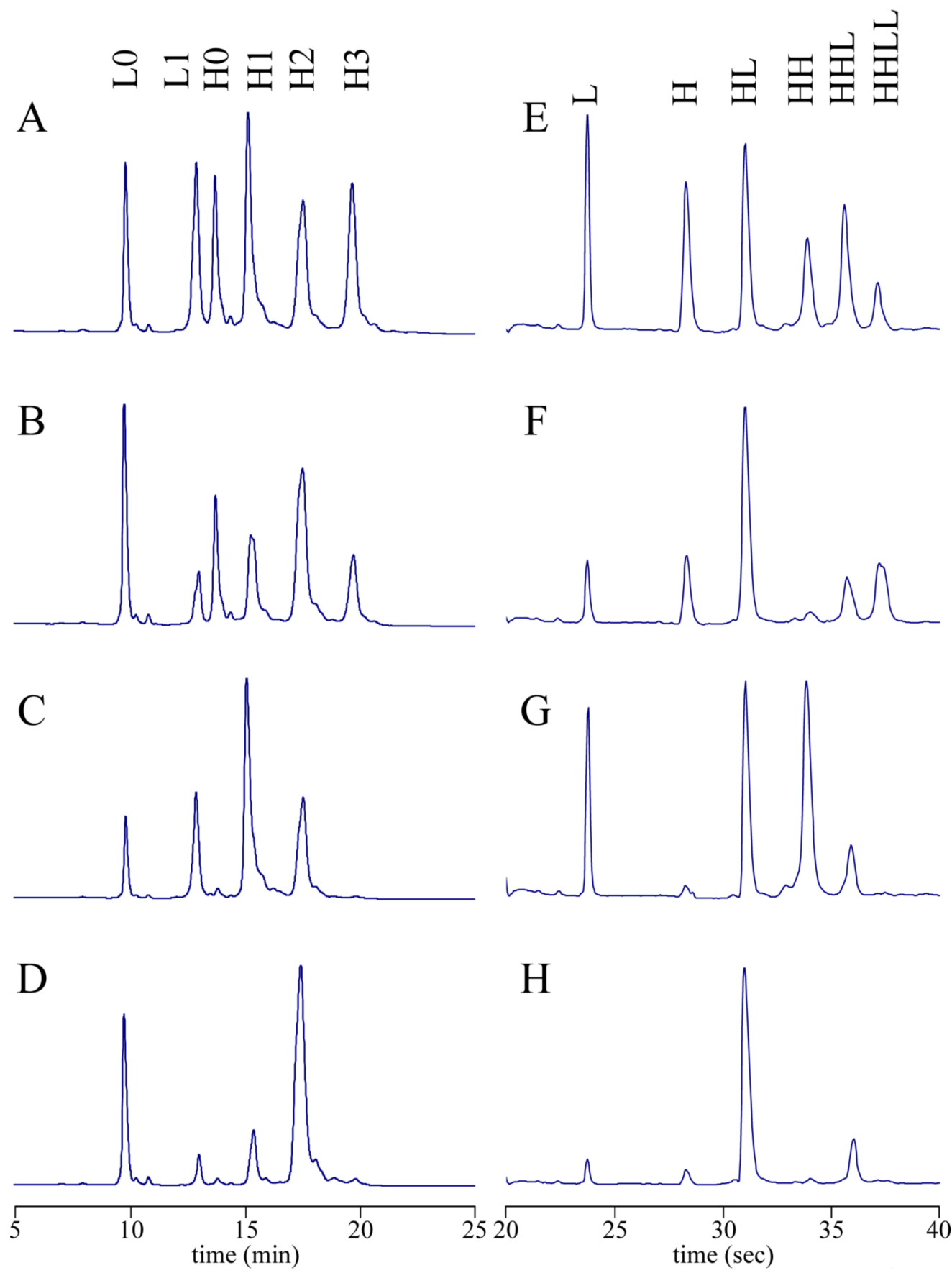

3.

Analytical characterization of ADCs. (A-D) Reversed-phase HPLC and (E-H) capillary electrophoresis were used to analyze (A, E) E4 mixture made by partial DTT reduction followed by MMAE conjugation; (B, F) E4 mixture made by DTNB partial reoxidation followed by MMAE conjugation; $(\mathrm{C}, \mathrm{G}) \mathrm{E} 4$ made by partial DTT reduction followed by MMAE conjugation and purified by preparative HIC ; and (D, H) E4 made by partial DTNB reoxidation followed by MMAE conjugation and purified by preparative HIC. HPLC injections were $20 \mu \mathrm{L}$ of $1 \mathrm{mg} / \mathrm{mL} \mathrm{cAC} 10$-vcMMAE treated with $20 \mathrm{mM}$ DTT for $15 \mathrm{~min}$ at $37^{\circ} \mathrm{C}$. Separations were performed at $80^{\circ} \mathrm{C}$. Capillary electrophoresis was performed under nonreducing conditions. 

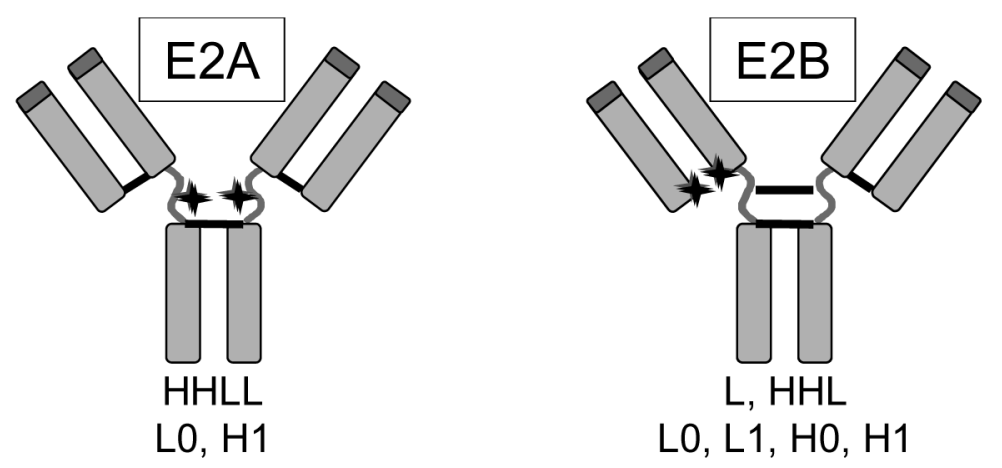

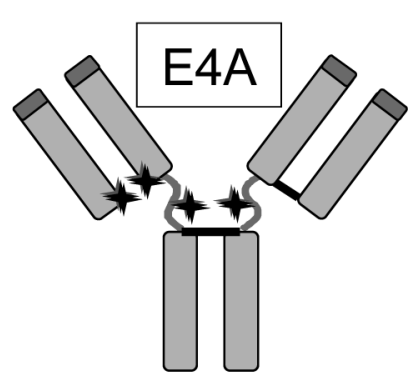

$\mathrm{L}, \mathrm{HHL}$

LO, L1, H1, H2

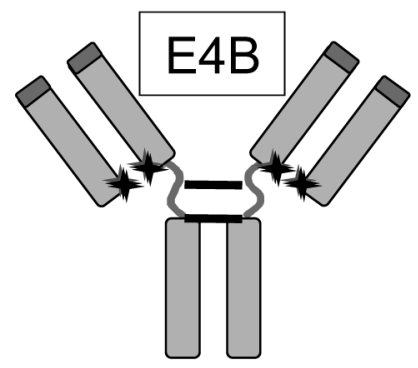

$\mathrm{L}, \mathrm{HH}$

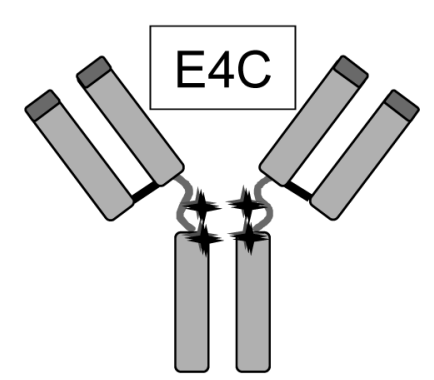

$\mathrm{HL}$

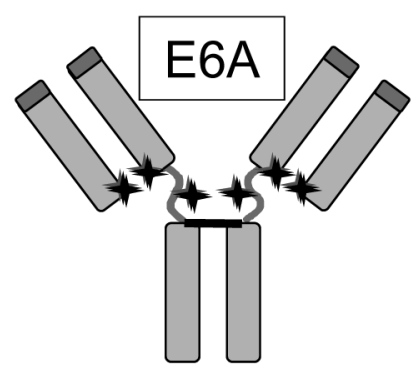

L1, H1

$$
\begin{aligned}
& \mathrm{L}, \mathrm{HH} \\
& \mathrm{L} 1, \mathrm{H} 2
\end{aligned}
$$

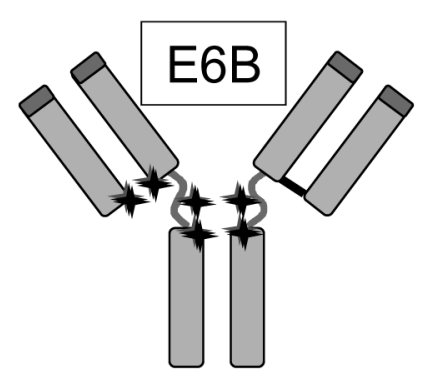

\author{
$\mathrm{L}, \mathrm{H}, \mathrm{HL}$
}

LO, L1, H2, H3

4.

Potential isomers for E2, E4, and E6. Isomers with one heavy-heavy disulfide (2A, 4A, and $6 \mathrm{~A})$ can be further subdivided into isomers with either the first or the second disulfide intact, but because the analytical methods described herein cannot distinguish these subgroups, only one isomer is shown. Below the isomer are the chain compositions under denaturing conditions (first line, non-reducing; second line, reducing). For denaturing and non-reducing conditions, the possible species formed are L, H, HL, HH, HHL, and LHHL, where the remaining interchain disulfides link the indicated chains. For denaturing and reducing, the possible species formed are $\mathrm{L} 0, \mathrm{~L} 1, \mathrm{H} 0, \mathrm{H} 1, \mathrm{H} 2$, and $\mathrm{H} 3$, in which the numbers indicate how many drug molecules are attached to the light or heavy chain. The locations of MMAE conjugation are indicated by stars. Unconjugated cAC10 (E0) and fully conjugated cAC10 (E8) are not shown. 


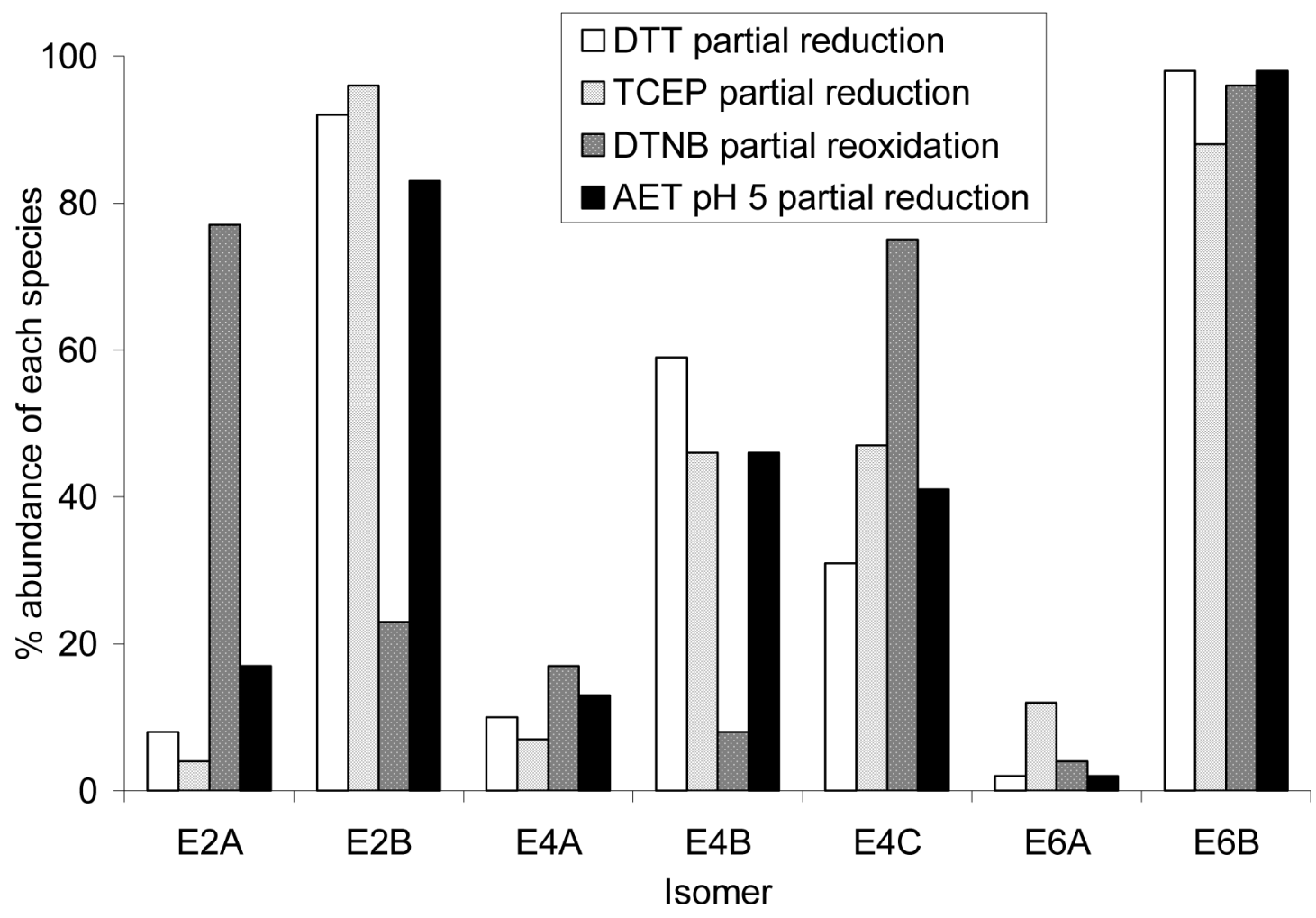

5.

Composition of isomeric population of purified E2, E4, and E6. The percent of the E2 and E6 isomers were determined from reversed-phase HPLC data using Equations 1 and 2,

respectively. The percent of E4A was determined from capillary electrophoresis data using Equation 3 and then the percent of $\mathrm{E} 4 \mathrm{~B}$ and $\mathrm{E} 4 \mathrm{C}$ were determined from reversed-phase HPLC data using Equations 4 and 5. For each drug loading level, the sum of the isomers is equal to $100 \%$. 

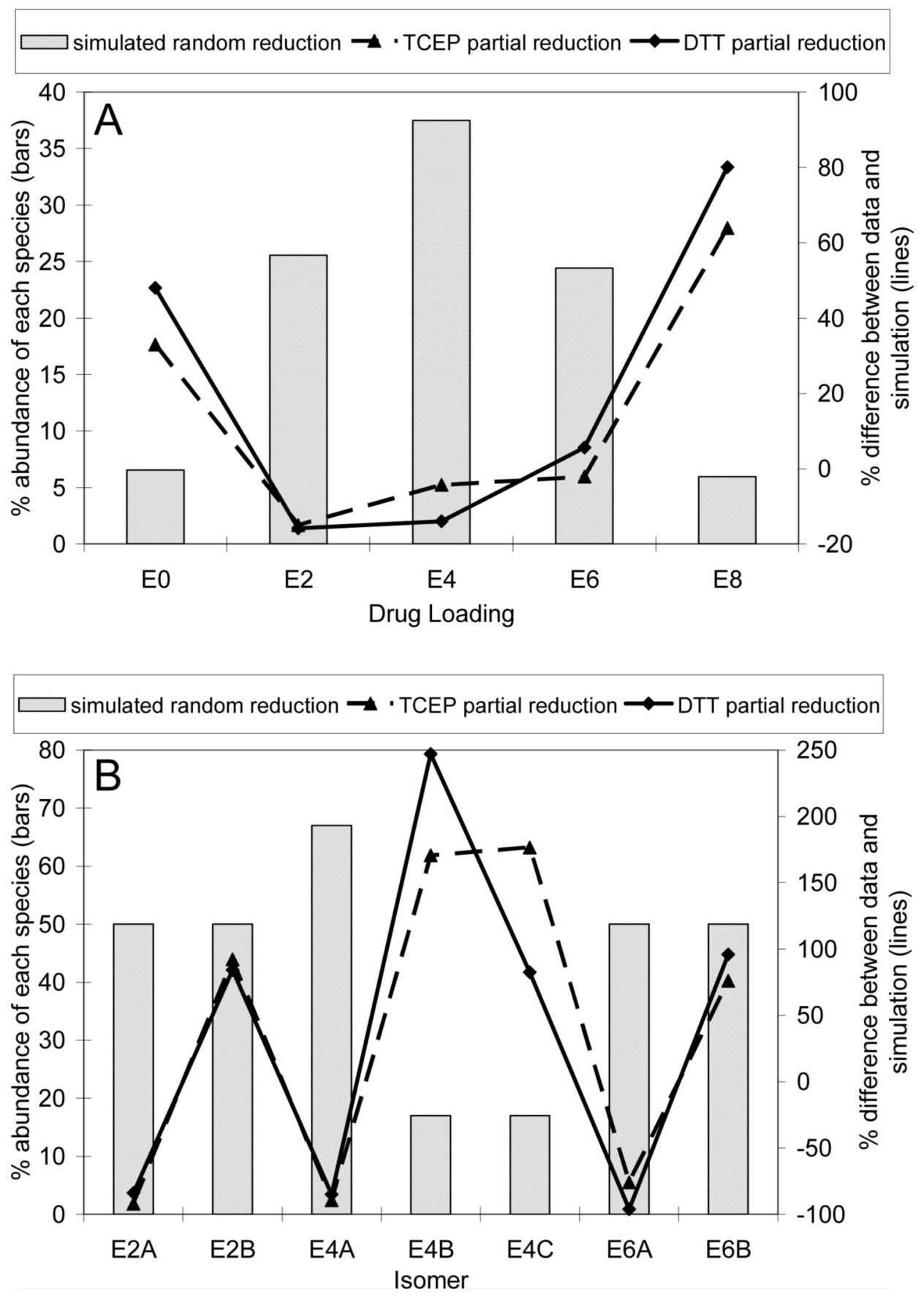

6.

Simulation of random reduction reaction. cAC10 reduction was simulated with equal rate constants for reduction of heavy-heavy and heavy-light disulfides. (A) The simulated drug loading abundance is shown with bars for the reduction of an average of 2 disulfides to yield an average of 4 antibody cysteines. The percent differences between the experimentally determined drug loading abundance from HIC-HPLC data for DTT and TCEP partial reduction shown in Figure 2 and the simulated values are shown in lines. (B) The simulated isomer distribution is shown in bars. The percent differences between the experimentally determined isomer abundances shown in Figure 5 and the simulated values are shown in lines. In both panels, a positive number indicates that the experimental data is greater than the simulated 
value, while a negative number indicates that the experimental data is lower than the simulated value. 

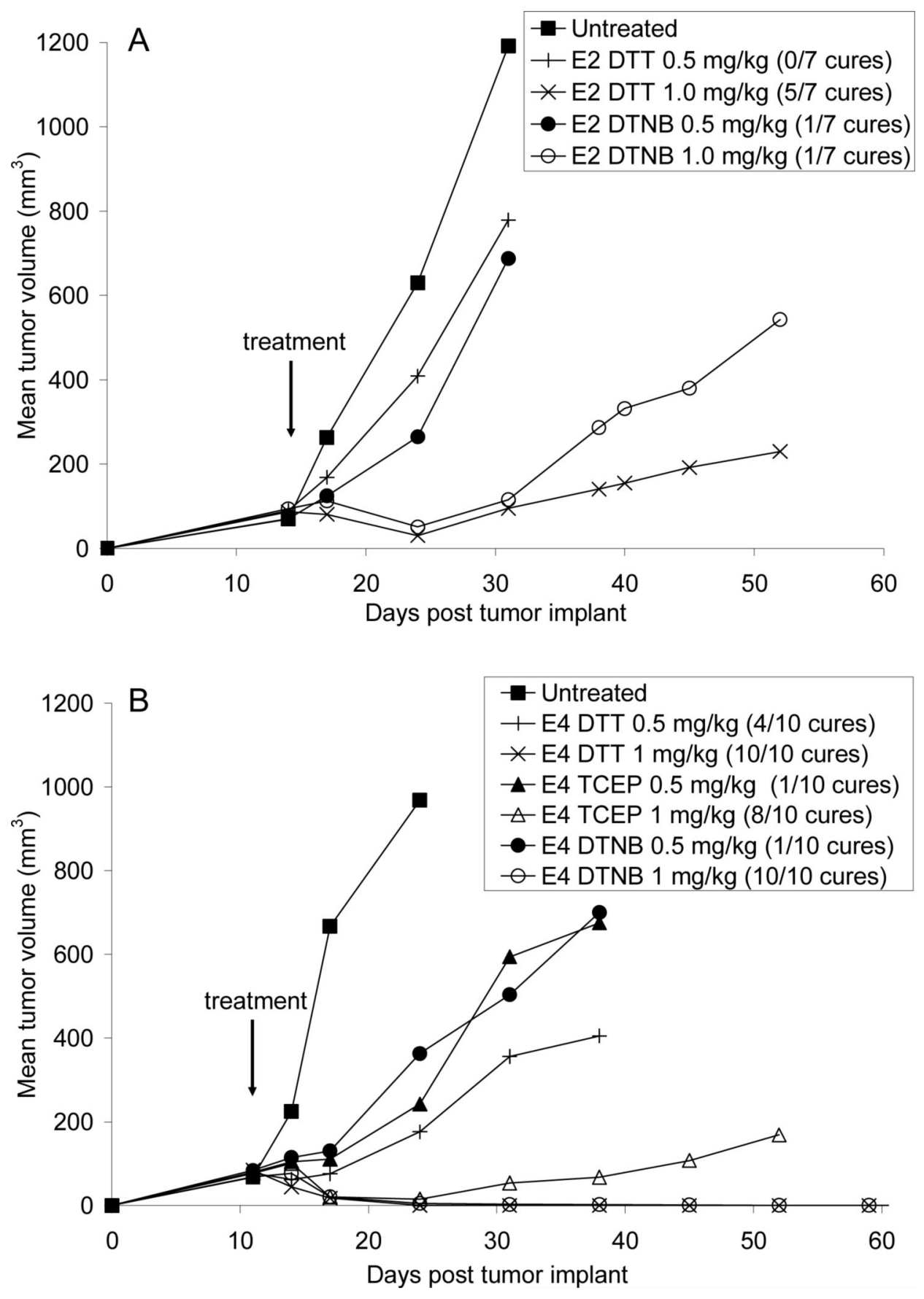

7.

Single dose efficacy of E2 and E4. SCID mice with Karpas 299 tumors were treated with single doses of (A) E2 made by DTT partial reduction and DTNB partial reoxidation and (B) E4 made by DTT partial reduction, TCEP partial reduction, and DTNB partial reoxidation. Animals were considered cured if they were tumor free 101 days post tumor implant. 
Sun et al.

Page 21

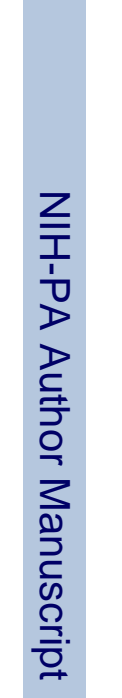

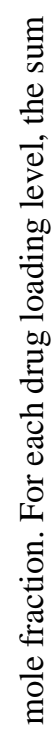

.$\Xi$
0
0
ปี
.

主 竞

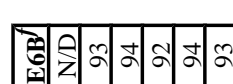

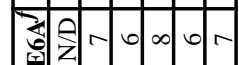

$>\frac{0}{\circ}$

容窎

文

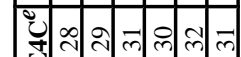

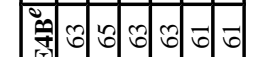

क

오.
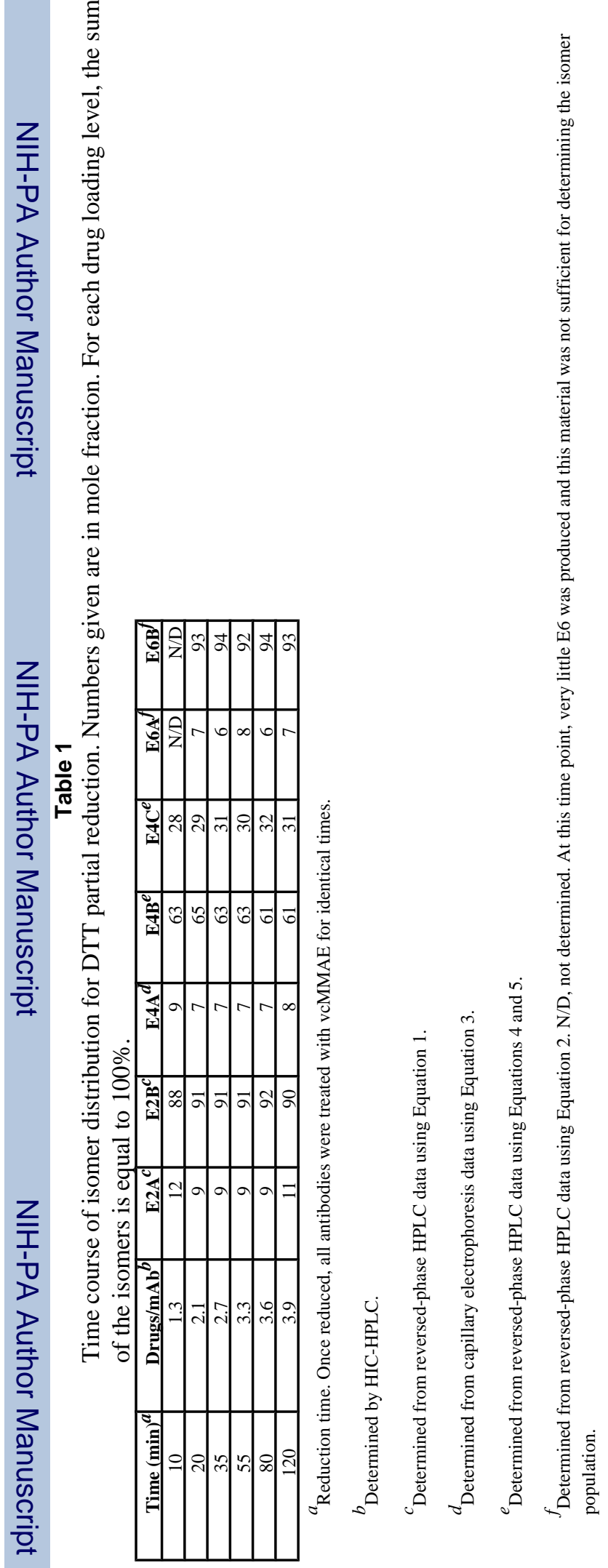

Bioconjug Chem. Author manuscript; available in PMC 2008 September 17. 
Table 2

In vitro binding and cytotoxicity of cAC10-vcMMAE.

\begin{tabular}{|c|c|c|}
\hline ADC & ${\text { Binding } \mathbf{K}_{\mathbf{d}}(\mathbf{n M})^{\mathbf{a}}}$ & ${\text { Karpas 299 } \mathbf{~ I C}_{\mathbf{5 0}}(\mathbf{n g} / \mathbf{m L})^{b}}^{\boldsymbol{b}}$ \\
\hline E0 (cAC10) & $2.70 \pm 1.91$ & N/D \\
\hline E2 mixture DTT & N/D & $11.4 \pm 2.4$ \\
\hline E2 DTT & $3.57 \pm 2.41$ & $13.8 \pm 3.6$ \\
\hline E2 mixture DTNB & N/D & $11.7 \pm 4.5$ \\
\hline E2 DTNB & $2.02 \pm 1.22$ & $13.2 \pm 2.7$ \\
\hline E4 mixture DTT & N/D & $3.4 \pm 1.2$ \\
\hline E4 DTT & $7.76 \pm 3.93$ & $4.8 \pm 0.7$ \\
\hline E4 mixture DTNB & N/D & $5.0 \pm 0.0$ \\
\hline E4 DTNB & $7.69 \pm 4.42$ & $4.3 \pm 0.9$ \\
\hline E8 & $6.53 \pm 3.09$ & $2.7 \pm 0.2$ \\
\hline
\end{tabular}

${ }^{a}$ Binding to Karpas 299, determined from 4-7 independent measurement \pm standard deviation. N/D, not determined.

${ }^{b}$ In vitro cytotoxicity, in ng cAC10/mL, determined from 3 independent measurements \pm standard deviation. N/D, not determined. cAC10 alone displays poor activity against Karpas 299. 